\title{
Seasonal variations in growth and body composition of 8-11-y-old Danish children
}

\author{
Stine-Mathilde Dalskov', Christian Ritz', Anni Larnkjær', Camilla T. Damsgaard', Rikke A. Petersen', Louise B. Sørensen', \\ Mads F. Hjorth', Ken K. Ong'², Arne Astrup', Christian Mølgaard' and Kim F. Michaelsen'
}

BACKGROUND: Earlier studies on seasonality in growth reported the largest height gains during spring and largest body weight gains during autumn. We examined seasonality in height, body weight, BMI, fat mass index (FMI), and fat-free mass index (FFMI) among contemporary Danish 8-11-y olds.

METHODS: A total of 760 children from the OPUS School Meal Study provided >2,200 measurements on height, body weight, and composition between September and June. Average velocities were calculated using change-score analyses based on 3-mo intervals. As a complementary analysis, point velocities derived from estimated growth curves were fitted using semiparametric regression that included covariate adjustment and allowed flexible modeling of the time trend.

RESULTS: Average velocities showed the following trends: height was higher than the average $(6.10 \mathrm{~cm} / \mathrm{y})$ in JanuaryApril. Body weight was below the average $(4.02 \mathrm{~kg} / \mathrm{y})$ in August-January and above in January-May; BMI (average: $0.49 \mathrm{~kg} / \mathrm{m}^{2} / \mathrm{y}$ ) and FFMI (average: $0.17 \mathrm{~kg} / \mathrm{m}^{2} / \mathrm{y}$ ) showed similar trends. In contrast, FMI was above the average $\left(0.38 \mathrm{~kg} / \mathrm{m}^{2} / \mathrm{y}\right)$ in November-March. Similar trends were seen for point velocities. CONCLUSION: Our findings suggest seasonality in growth and body composition of Danish children. We recovered the well-known height velocity peak during spring time, but unlike earlier studies, we found coincident peaks in body weight, BMI, and FFMI velocities.

G rowth monitoring is an important part of child health provision throughout the world. To better detect growth disorders, it is important to have several repeated measurements and to understand the normal fluctuations in growth across different phases in childhood. Season of measurement could be of importance, especially when the period of growth monitoring is short. Studies on seasonal variation in growth of school-aged children in the northern hemisphere between 1886 and 1971 reported that the fastest height velocity occurs during spring or summer (1-6), while the fastest weight gain occurs during autumn or early winter $(1,2,4-8)$. However, in later years, the picture is less clear. Among Japanese children, the seasonal variation in height and weight gains was attenuated from
1959-1963 to 1971-1975 (9), and no seasonal variation was detectable in 1982-1984 (10). However, two small studies from the 1990s from the United Kingdom and Sweden reported seasonal variations in height $(11,12)$ and body weight $(12)$ gains, and seasonal variation in circulating insulin-like growth factor 1 levels that were consistent with short-term variations in body weight and BMI and also consistent with long-term variations in height velocity (13). Furthermore, children treated for growth hormone deficiency showed the largest height velocity responses during spring and early summer (14) or when experiencing the largest sunlight exposure (15), despite equal doses of growth hormone throughout the year. Most modern studies on temporal variation in children's body weight focus on differences between the summer holiday and the school year. They show that weight gain peaks during the summer holiday in overweight children but not in normal weight children $(16,17)$. Reasons for seasonal variation in growth may be related directly or indirectly to meteorology or cultural factors. The daily darklight cycle influences the production of melatonin (18), which has been shown to stimulate secretion of growth hormone (19). However, as suggested from the studies of growth hormone therapy, seasonality in growth hormone response is also apparent. Sunlight exposure and temperature could also influence production of other hormones that regulate growth and body weight, such as insulin-like growth factor 1 (13), leptin, and ghrelin (20). Indirect effects of meteorology could include food availability $(1,9)$, infectious diseases (7), physical activity, and sleep habits $(21,22)$. The larger summer holiday weight gains observed in overweight children could reflect less disciplined lifestyles and absence of school-related physical activity (16).

The aim of the present paper is to examine if seasonal variations in height, body weight, BMI, fat mass index (FMI), and fat-free mass index (FFMI) velocities still exist in a contemporary school-aged children in a high-income Danish setting.

\section{RESULTS}

Among children with data from baseline (August-November), $47 \%$ of girls and $23 \%$ of boys had entered puberty (Table 1 ). The prevalence of overweight (including obesity) was 12.7 and $13.3 \%$ for girls and boys and for underweight, the numbers 
were 12.2 and $8.5 \%$ for girls and boys, respectively (Table 1 ). Children in the present study were representative of Danish children with regard to prevalence of overweight, while their household educational level was slightly higher than the average for Danish families with children (23).

\section{Height Velocity}

Average velocity in height for period 5 with midpoint 18 March was higher than the overall all-year change (Table 2).

Table 1. Baseline characteristics ${ }^{\mathrm{a}}$ for the study population $(N=760)$ by gender

\begin{tabular}{|c|c|c|c|c|}
\hline & $n$ & Girls $^{b}$ & $n$ & Boys $^{b}$ \\
\hline Age $(y)$ & 372 & $9.9(9.4,10.4)$ & 388 & $10.1(9.5,10.5)$ \\
\hline $\begin{array}{l}\text { Puberty ( } \% \\
\text { entered puberty) }\end{array}$ & 372 & 47 & 388 & 23 \\
\hline Height $(\mathrm{cm})$ & 368 & $142.3(137.3,146.7)$ & 386 & $142.9(138.0,147.3)$ \\
\hline Body weight (kg) & 368 & $33.6(29.7,38.2)$ & 386 & $34.2(30.2,39.6)$ \\
\hline $\mathrm{BMI}\left(\mathrm{kg} / \mathrm{m}^{2}\right)$ & 368 & $16.6(15.3,18.3)$ & 386 & $16.7(15.6,18.5)$ \\
\hline Prevalence $(\%)^{c}$ & 368 & & 386 & \\
\hline $\begin{array}{l}\text { Overweight } \\
\text { (incl. obese) }\end{array}$ & & 12.7 & & 13.5 \\
\hline Underweight & & 12.2 & & 8.5 \\
\hline FMI $\left(\mathrm{kg} / \mathrm{m}^{2}\right)$ & 368 & $4.1(2.9,5.6)$ & 386 & $3.1(2.2,4.8)$ \\
\hline FFMI $\left(\mathrm{kg} / \mathrm{m}^{2}\right)$ & 368 & $12.4(11.8,13.1)$ & 386 & $13.4(12.8,14.1)$ \\
\hline
\end{tabular}

FFMI, fat-free mass index; FMI, fat mass index.

aFor age and pubertal status, baseline data are available for all the 760 included children, while for the remaining variables, the number is 754 . ${ }^{\mathrm{b}}$ Median (interquartile range) or percentages are presented. 'Based on age- and sex-specific cutoffs defined to pass through BMl of 18.5 and $25 \mathrm{~kg} / \mathrm{m}^{2}$ at age $18 \mathrm{y}$, as according to Cole et al. $(25,26)$.
This spring peak in height velocity was also seen in the point velocities (Figure 1a).

\section{Body Weight and BMI Gains}

Average velocities in body weight and BMI for periods 5 and 6 (midpoints 18 March and 20 April) were higher than the overall all-year change (Table 2). During the autumn and early winter period (period 1: midpoint 24 October and period 2: midpoint 6 December), average velocities were lower than the all-year change (Table 2). Also when looking at point velocities for gain in body weight and BMI, higher than average velocities were seen during spring months and lower than average velocities during the autumn (Figure $\mathbf{1 b}, \mathbf{c}$ ).

\section{Changes in Body Composition}

For FMI, average velocities were higher than the all-year average for the periods 3 and 4 (midpoints 8 January and 1 February) (Table 2). Likewise the corresponding point velocities were higher than the all-year average between ultimo December and ultimo February (Figure 1d). FMI average velocities were lower than the all-year average for period 1 (midpoint 24 October) (Table 2), which matched the corresponding point velocities that were lower than the all-year average between ultimo September and ultimo December (Figure 1d). Average velocities for FFMI were higher than the all-year average during the same spring time periods as body weight and BMI (periods 5 and 6 with midpoints 18 March and 20 April) and lower than average across autumn and early winter periods (periods $1-3$ with midpoints 24 October, 6 December, and 8 January) (Table 2), a trend also seen for the point velocities (Figure 1e).

Table 2. Estimated average velocities in height, body weight, and body composition depending on the time of measurements for children with data from three time points (baseline, $3 \mathrm{mo}$, and $6 \mathrm{mo}, n=692-705$ )

\begin{tabular}{|c|c|c|c|c|c|c|c|}
\hline & \multicolumn{6}{|c|}{ Average velocity based on 3-mo changes } & \multirow{2}{*}{$\begin{array}{c}\begin{array}{c}\text { All-year } \\
\text { change }^{\text {b }}\end{array} \\
\text { Across all } \\
\text { periods }\end{array}$} \\
\hline & Period 1 & Period 2 & Period 3 & Period 4 & Period 5 & Period 6 & \\
\hline & \multicolumn{7}{|c|}{ Midpoint } \\
\hline & 24 October & 6 December & 8 January & 1 February & 18 March & 20 April & 25 January \\
\hline Height (cm) & $\begin{array}{c}6.17(5.82,6.52) \\
\quad(n=236)\end{array}$ & $\begin{array}{c}6.05(5.72,6.38) \\
(n=249)\end{array}$ & $\begin{array}{c}5.76(5.47,6.04) \\
\quad(n=220)\end{array}$ & $\begin{array}{c}5.82(5.53,6.10) \\
(n=243)\end{array}$ & $\begin{array}{c}6.59(6.24,6.93)^{c} \\
(n=243)\end{array}$ & $\begin{array}{c}5.93(5.61,6.24) \\
\quad(n=219)\end{array}$ & $\begin{array}{c}6.06(5.93,6.18) \\
(n=705)\end{array}$ \\
\hline BMI $\left(\mathrm{kg} / \mathrm{m}^{2}\right)$ & $\begin{array}{c}-0.45(-0.68,-0.23)^{d} \\
(n=236)\end{array}$ & $\begin{array}{c}0.27(0.05,0.48)^{d} \\
(n=248)\end{array}$ & $\begin{array}{c}0.61(0.41,0.81) \\
\quad(n=220)\end{array}$ & $\begin{array}{c}0.73(0.52,0.94) \\
(n=243)\end{array}$ & $\begin{array}{c}0.93(0.72,1.13)^{c} \\
(n=242)\end{array}$ & $\begin{array}{c}0.90(0.68,1.13)^{c} \\
(n=219)\end{array}$ & $\begin{array}{c}0.50(0.42,0.59) \\
(n=704)\end{array}$ \\
\hline FMI $\left(\mathrm{kg} / \mathrm{m}^{2}\right)$ & $\begin{array}{c}-0.18(-0.37,0.00)^{\mathrm{d}} \\
(n=233)\end{array}$ & $\begin{array}{c}0.29(0.11,0.47) \\
(n=243)\end{array}$ & $\begin{array}{c}0.87(0.69,1.05)^{c} \\
(n=216)\end{array}$ & $\begin{array}{c}0.68(0.51,0.86)^{c} \\
(n=240)\end{array}$ & $\begin{array}{c}0.49(0.31,0.66) \\
(n=237)\end{array}$ & $\begin{array}{c}0.34(0.16,0.53) \\
\quad(n=215)\end{array}$ & $\begin{array}{c}0.42(0.35,0.49) \\
(n=692)\end{array}$ \\
\hline
\end{tabular}

FFMI, fat-free mass index; FMI, fat mass index.

aEstimated annual changes (reported as mean, 95\% confidence interval, and number of observations $n$ ) were based on 3-mo changes with different starting dates (as indicated by the intervals) during a school year (periods 1-6). The vast majority of children providing data for periods 1 and 4,2 and 5 , and 3 and 6 were the same. Periods were constructed so that they included similar numbers of observations. Starting intervals for the six periods were: period 1 (30 August-27 September), period 2 ( 28 September-4 November), period 3 ( $8-28$

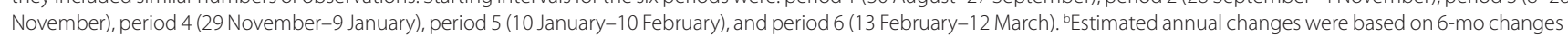
without distinction between time periods with different starting points. The estimate annual change for that time period is higher than the estimated annual change across all time periods (two-sample $t$-test, $P<0.05$ ). ${ }^{\mathrm{d}}$ The estimate annual change for that time period is lower than the estimated annual change across all time periods (two-sample $t$-test, $P<0.05$ ). 
a

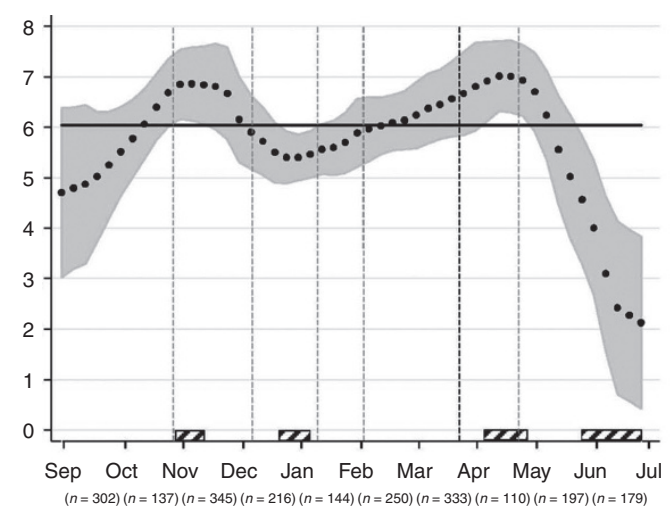

c

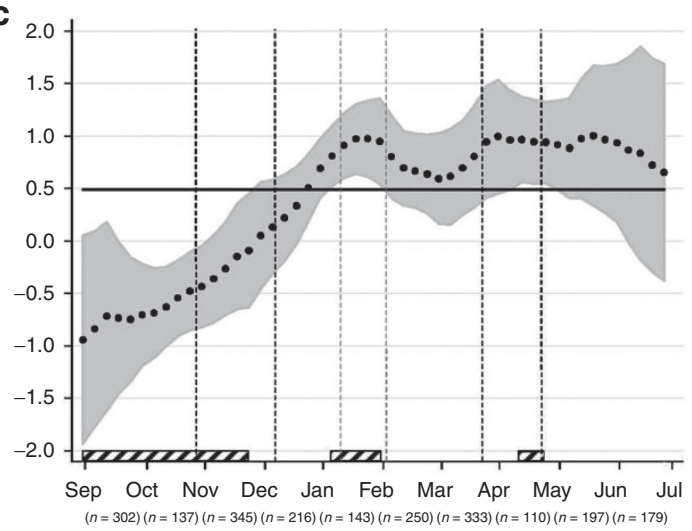

b

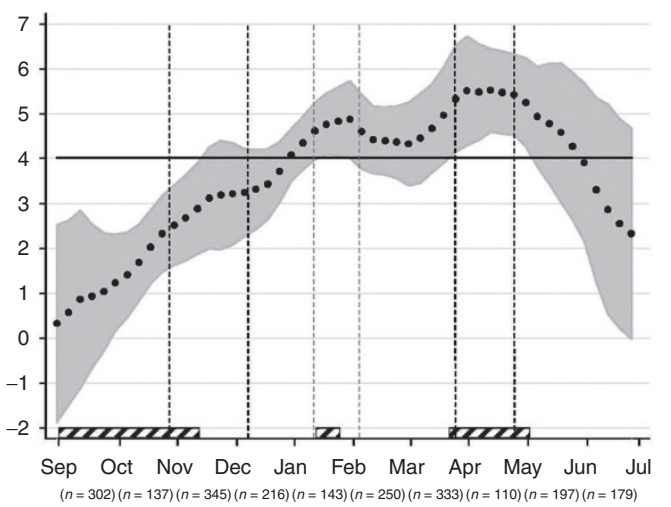

d

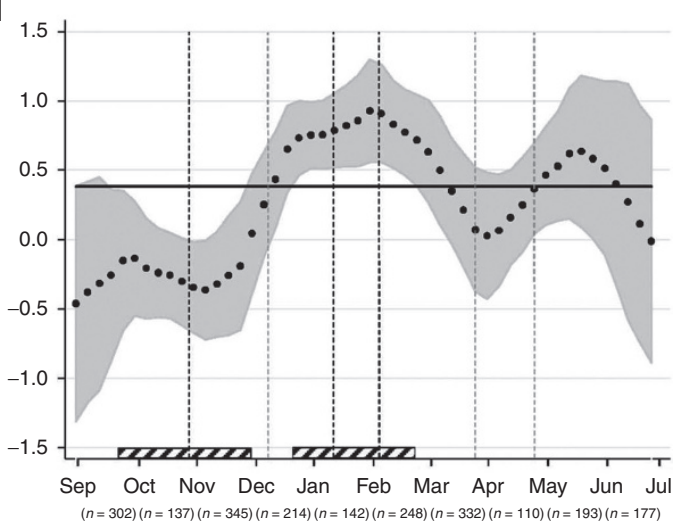

e

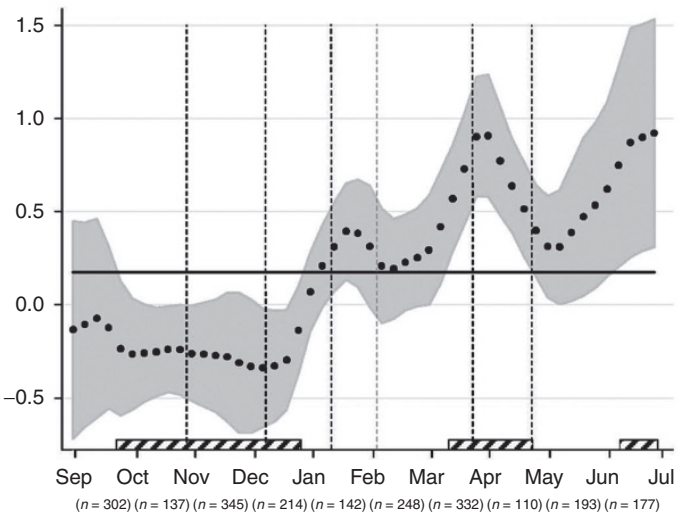

Figure 1. Point velocities vs. all-year linear average for growth and body composition of 8-11-y-old children. (a) Height velocity (cm/y), (b) body weight velocity $(\mathrm{kg} / \mathrm{y})$, (c) BMI velocity $\left(\mathrm{kg} / \mathrm{m}^{2} / \mathrm{y}\right)$, (d) fat mass index velocity $\left(\mathrm{kg} / \mathrm{m}^{2} / \mathrm{y}\right)$, and (e) fat-free mass index velocity $\left(\mathrm{kg} / \mathrm{m}^{2} / \mathrm{y}\right)$. Black dots: point velocities; grey areas: $95 \%$ confidence interval for point velocities; black horizontal lines: all-year average; striped areas: time periods with point velocities $\neq$ all-year average $(P<0.05)$. Vertical dashed lines are based on the analyses presented in Table $\mathbf{2}$ (to ease comparison between the results from the two types of analyses) and illustrates midpoints for the six periods for which 3-mo changes were translated into annual average velocities (black if different and grey if not different from an overall all-year velocity calculated across periods).

\section{DISCUSSION}

Our findings for height are in agreement with results from previous studies (1-6). The lower than average gains in body weight, BMI, FMI, and FFMI in autumn are in contrast to the majority of previous studies showing the highest gain in body weight (no studies with data on body composition) during autumn or early winter $(1,2,4-8)$. Our results on body composition suggest that the higher body weight gain during spring is due to fat-free mass rather than fat mass. A higher level of physical activity during spring than during winter may be a likely explanation for the changes in gains in body weight and body composition during winter and spring (22).

Two newer studies are comparable with our study regarding latitude and population characteristics $(11,12)$. Gelander et al. found a peak in height velocity during spring among 50 Swedish 7-11-y olds measured in 1992-1993 (11); no data were available on weight or body composition. Their study setup was different from ours having fewer study subjects $(n=50)$, but more frequent measurements and comparing monthly based growth rates with each other, not with an all-year linear 
trend (11). Based on data from prepubertal British children, Tillmann et al. concluded that in addition to a strong seasonal trend (height and body weight gains both highest during spring), linear growth was comprised of three to six yearly growth spurts separated by stasis, whereas weight gain was characterized by two to five periods of weight gain separated by periods of weight loss (12). Their study setup differed from ours by having fewer study subjects $(n=43)$, but more frequent measurements (biweekly for 1 y) and reporting average number, length and amplitude of height velocity peaks, and periods with growth stasis, weight gain, and weight loss based on averages of smooth estimates from individual height and weight velocity profiles (12).

Most of the previous studies on seasonal variation in growth are not contemporary and results may reflect seasonal variations in food availability $(1,9)$, impacts of infectious diseases (7), or other factors which are less relevant in contemporary cohort of school-aged children in highincome countries. Seasonal variations in physical activity and sleep may also be different today, where physical activity is predominantly due to playing and sports, not, e.g., due to physical work, and where sleep duration may be less influenced by day length.

A limitation of our study is that our collection of data was not designed with a view to study seasonal variations in growth, and thus we had a maximum of three measures per child and no data available for the summer holiday (July and most of August). The large number of children measured and the complementary statistical modeling of point velocities with careful adjustment for factors related to the design of the study and the individual child may to some extent counterbalance the shortcoming of the study design. However, we cannot rule out the possibility that results do not reflect true seasonality in growth but simply are due to modeling artifacts. The choice of modeling assumptions for the semiparametric regression approach (e.g., smoothing algorithm and bandwidth selection) may also have an impact on the resulting estimated growth curves and the derived point velocities. Therefore, these results, which were obtained using a completely different modeling approach as compared to the change-score analysis, were used to support the findings seen for average velocities. In view of the exploratory nature of this study, $P$ values and confidence bands should be viewed as very conservative indications of the variability in the estimates.

Moreover, hypothetically some of the seasonal differences in growth velocity could be due to the dietary intervention. In a previous publication, we demonstrated a gain in FMI of $0.03 \mathrm{~kg} / \mathrm{m}^{2}$ (95\% confidence interval: $0.00,0.05 ; P=0.04$ ) during the intervention period compared with the control period (24). However, there was no modifying effect of the order of the diets, which means that this small effect of the intervention on FMI is evenly distributed across the school year and thus is unlikely to explain seasonal variations in FMI. Height, BMI $z$-score, and FFMI were not influenced by the intervention (24).
The present study showed that gains in height and body weight and changes in body composition vary considerably with season. These findings need to be confirmed in future studies that are designed to minimize bias partly caused by different children characterizing growth in different time periods or even seasons. Specifically, such designs should ensure that children are followed for a longer time span, resulting in more observations per child (and possibly less children in total as compared to the present study). Consequently, individual growth trajectories would also to a much larger extent become overlapping. Moreover, measurements should cover the entire calendar year, also summer holidays and other school breaks in order to avoid spurious boundary effects.

\section{Conclusions}

Our findings suggest substantial seasonality in growth and body composition of contemporary Danish children. We recovered the well-known height velocity peak during spring time, but unlike earlier studies, we found coincident peaks in body weight, BMI, and FFMI velocities.

\section{METHODS}

\section{Protocol}

OPUS School Meal Study is a cluster-randomized, cross-over controlled, and unblinded study carried out between the 30th of August 2011 and the 26th of June 2012. Overall study aim, design, recruitment, power calculation, randomization, and drop-outs have been described previously (23). Briefly, children from third and fourth grades (8-11 y) at nine schools in the eastern part of Denmark were invited to participate in the study. Exclusion criteria for the children were strong food allergies or food intolerances or concomitant participation in other scientific studies that involved radiation or blood sampling. Each child participated in two 3-mo periods: an intervention period with provision of meals based on the so-called New Nordic Diet and a control period. Investigations were carried out three times in each child: at baseline, between the two dietary periods, and after the last dietary period. The study was conducted according to the guidelines laid down in the Declaration of Helsinki and all procedures involving human subjects were approved by the Regional Committee on Biomedical Research Ethics of the Capital Region of Denmark (no. H-1-2010-124). Written informed consent was obtained from custody holders of the child. The trial was registered in the Clinical Trials database (clinicaltrials.gov; no. NCT01457794). In this paper, we did not test the effects of the intervention but performed observational analyses of the longitudinal study data, adjusting for factors related to the design of the study.

\section{Measurements}

Pubertal status. At baseline, an interviewer carried out an in-depth personal interview with one of the parents. Baseline pubertal status (breast development in girls and emergence of pubertal hair in boys) was self-evaluated based on Tanner staging categorizing the children into one of five categories as validated by Morris and Udry (25). The variable was recoded to a binary variable: not entered puberty (stage 1 ) or entered puberty (stage $2-5$ ).

Anthropometric measurements. Clinical examinations were performed at baseline, $3 \mathrm{mo}$, and $6 \mathrm{mo}$. Height was measured to the nearest $0.1 \mathrm{~cm}$ using a portable stadiometer (CMS Weighing Equipment LTD, London, UK) and body weight measured to the nearest $0.1 \mathrm{~kg}$ using a digital weight (Tanita BWB 800 S, Arlington Heights, Illinois). The measurements were carried out in the morning after an overnight fast. Children were asked to empty their bladder prior to the measurements and wore only light clothing. BMI was calculated and prevalence of underweight and overweight including obesity were based on 
age- and sex-specific cutoffs defined to pass through BMI of 18.5 and $25 \mathrm{~kg} / \mathrm{m}^{2}$ at age $18 \mathrm{y}$ according to Cole et al. $(26,27)$.

Whole-body composition of the children was measured by dualenergy X-ray absorptiometry scanning (Lunar Prodigy; GE Medical Systems (Madison, Wisconsin) with Encore software version 13.5). Approximately $85 \%$ of the children had a standardized breakfast prior to the scanning. FMI and FFMI were calculated as originally described by VanItallie et al. (28):

FMI $\left(\mathrm{kg} / \mathrm{m}^{2}\right)=($ Fat mass $(\mathrm{kg})) /(\text { Height }(\mathrm{m}))^{2}$

FFMI $\left(\mathrm{kg} / \mathrm{m}^{2}\right)=($ Lean mass $(\mathrm{kg})+$ Bone mineral content $(\mathrm{kg})) /$ $(\text { Height }(\mathrm{m}))^{2}$

In a study on the reproducibility of whole-body scans of 5-17-y-old children using the GE Lunar, coefficients of variation of $1.94 \%$ (fat mass) and $0.48 \%$ (fat-free mass) were found for two repeated scans in thin mode (29).

To be included in the analyses, children had to have data on age and pubertal status at baseline and in addition have measures of body weight, height, and body composition from at least two time points (any combination of baseline, $3 \mathrm{mo}$, and $6 \mathrm{mo}$ ). One boy with achondroplasia was excluded from the analyses.

\section{Data Analysis}

Descriptive statistics were calculated for demographics and body composition. Medians and interquartile range were calculated for continuous variables, and frequencies were calculated for discrete variables.

We considered two complementary statistical approaches: a change-score analysis resulting in average velocities and a semiparametric regression analysis involving analysis of covariance-type linear mixed models and producing point velocities derived from growth curves. The former approach is simple and robust, whereas the latter approach includes various adjustments and allows more flexibility in modeling trends.

In the first approach, 3-mo changes in height, body weight, BMI, FMI, and FFMI (from baseline to $3 \mathrm{mo}$ and again from 3-6 mo) were calculated for children with data from all three time points. These 3-mo changes were translated into annual average (growth) velocities and categorized into one of six periods according to their starting time point (season). Each of these six period-specific velocities was compared with the overall all-year change (across periods) by means of a two-sample $t$-test. The second approach involved fitting semiparametric regression models (30-32). Initially, covariate information reflecting differences between children was incorporated in (parametric) linear mixed models that were fitted to each outcome considered. From each model fit, we retrieved the raw (unstandardized) residuals for further analysis. These residuals may be viewed as adjusted outcome values, adjusted for child-specific differences captured in the explanatory variables that were included in the linear mixed models. Specifically, analysis of covariance-type hierarchical linear mixed models with child, class, year group within school, and school as random effects were fitted. In addition to the effect of time (included as a continuous variable), models were adjusted for age at baseline and the interaction between gender and pubertal status at baseline. FMI was square root-transformed for analysis and subsequently estimates were back-transformed and presented on the original scale $\left(\mathrm{kg} / \mathrm{m}^{2}\right)$ as suggested by Laursen et al. (33). Model checking was based on visual inspection of residual and normal probability plots.

Subsequently, growth trends in the residuals were modeled using local linear regression, a nonparametric method for fitting a growth curve where many simple linear regressions were fitted locally, at each time point but confined to a small time interval centered around each time point (determined by a bandwidth) and with decreasing weights towards interval endpoints. Weights were calculated using the triangular kernel. Based on an interquartile range from 72 to 210 $\mathrm{d}$ and a total number of observations $\sim 2,200$, the minimum bandwidth was found to be $24 \mathrm{~d}$ according to Silverman's rule of thumb (34). However, we used a larger bandwidth of $48 \mathrm{~d}(24+24)$, allowing for smooth local regression curves despite gaps of up to $24 \mathrm{~d}$ without measurements, such as around the Christmas holiday. First derivatives (i.e., point velocities) were readily obtained from the estimated growth curves through differentiation (35). We estimated $95 \%$ confidence interval for the point velocities based on the SE from the initial linear mixed model combined with the standard error from

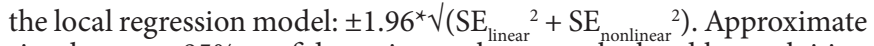
simultaneous $95 \%$ confidence intervals were calculated by exploiting correlation between neighboring time points and the corresponding $P$ values were adjusted accordingly for multiplicity (36).

All statistical analyses were carried out using STATA/IC 13.0 (College Station, TX).

\section{ACKNOWLEDGMENT}

We thank the children and their parents for their participation and the schools for their cooperation.

\section{STATEMENT OF FINANCIAL SUPPORT}

The "Optimal well-being, development and health for Danish children through a healthy New Nordic Diet" (OPUS) study was financed by a grant from the Nordea Foundation (Copenhagen, Denmark, grant number 02-2010-478 0389). A complete list of food suppliers providing full or partial food sponsorships to the study can be found at the website: http:// foodoflife.ku.dk/opus/wp/skolemadsprojektet/leverandorer/. All food suppliers were located in Denmark. Sources of funding and donation had no role in the trial design; collection, analysis, or interpretation of data; or decision to publish.

Disclosure: S.-M.D., C.R., A.L., C.T.D., R.A.P., L.B.S., M.F.H., K.K.O., K.F.M., and C.M. declare no conflicts of interest. A.A. is consultant/member of advisory boards for the Dutch Beer Knowledge Institute, NL; Global Dairy Platform, USA; McCain Foods Limited, USA; McDonald's, USA.

\section{REFERENCES}

1. Malling-Hansen R. Periods in Growth of Children and in the Heat of the Sun: Empirical Findings. Copenhagen, Denmark: Hoffenberg \& Traps Etablissement, 1886.

2. Bransby ER. The seasonal growth of children. Med Off 1945;73:149, 157, 165.

3. Marshall WA. Evaluation of growth rate in height over periods of less than one year. Arch Dis Child 1971;46:414-20.

4. Orr JB, Clark ML. A report on seasonal variation in the growth of schoolchildren. Lancet 1930;216:365-7.

5. Reynolds EL, Sontag LW. Seasonal variations in weight, height and appearance of ossification centres. J Pediatr 1944;24:524.

6. Takahashi E. Growth and environmental factors in Japan. Hum Biol 1966;38:112-30.

7. Emerson H. Seasonal variation in growth of school children. JAMA 1927;89:1326-31.

8. Porter TW. The seasonal variation in the growth of Boston school children. Am J Phys 1920;52:121-31.

9. Kondo S, Takahashi E, Kato K, Takahashi S, Ikeda M. Secular trends in height and weight of Japanese pupils. Tohoku J Exp Med 1978;126:203-13.

10. Ikeda $M$, Watanabe $T$. Constant growth of primary school children throughout four seasons of year. Tohoku J Exp Med 1985;145:413-8.

11. Gelander L, Karlberg J, Albertsson-Wikland K. Seasonality in lower leg length velocity in prepubertal children. Acta Paediatr 1994;83:1249-54.

12. Tillmann V, Thalange NK, Foster PJ, Gill MS, Price DA, Clayton PE. The relationship between stature, growth, and short-term changes in height and weight in normal prepubertal children. Pediatr Res 1998;44:882-6.

13. Gelander L, Blum WF, Larsson L, Rosberg S, Albertsson-Wikland K. Monthly measurements of insulin-like growth factor I (IGF-I) and IGF-binding protein-3 in healthy prepubertal children: characterization and relationship with growth: the 1-year growth study. Pediatr Res 1999;45:377-83.

14. Land C, Blum WF, Stabrey A, Schoenau E. Seasonality of growth response to GH therapy in prepubertal children with idiopathic growth hormone deficiency. Eur J Endocrinol 2005;152:727-33.

15. Shulman DI, Frane J, Lippe B. Is there "seasonal" variation in height velocity in children treated with growth hormone? Data from the National Cooperative Growth Study. Int J Pediatr Endocrinol 2013;2013:2.

16. Baranowski T, O'Connor T, Johnston C, et al. School year versus summer differences in child weight gain: a narrative review. Child Obes 2014;10:18-24. 
17. Rodriguez AX, Olvera N, Leung P, O'Connor DP, Smith DW. Association between the summer season and body fatness and aerobic fitness among Hispanic children. J Sch Health 2014;84:233-8.

18. Luboshitzky R, Yanai D, Shen-Orr Z, Israeli E, Herer P, Lavie P. Daily and seasonal variations in the concentration of melatonin in the human pineal gland. Brain Res Bull 1998;47:271-6.

19. Valcavi R, Zini M, Maestroni GJ, Conti A, Portioli I. Melatonin stimulates growth hormone secretion through pathways other than the growth hormone-releasing hormone. Clin Endocrinol (Oxf) 1993;39:193-9.

20. Cahill S, Tuplin E, Holahan MR. Circannual changes in stress and feeding hormones and their effect on food-seeking behaviors. Front Neurosci 2013;7:140.

21. Gracia-Marco L, Ortega FB, Ruiz JR, et al.; Helena Study Group. Seasonal variation in physical activity and sedentary time in different European regions. The HELENA study. J Sports Sci 2013;31:1831-40.

22. Hjorth MF, Chaput JP, Michaelsen K, Astrup A, Tetens I, Sjödin A. Seasonal variation in objectively measured physical activity, sedentary time, cardio-respiratory fitness and sleep duration among 8-11 yearold Danish children: a repeated-measures study. BMC Public Health 2013;13:808.

23. Damsgaard CT, Dalskov SM, Petersen RA, et al. Design of the OPUS School Meal Study: a randomised controlled trial assessing the impact of serving school meals based on the New Nordic Diet. Scand J Public Health 2012;40:693-703.

24. Damsgaard CT, Dalskov SM, Laursen RP, et al. Provision of healthy school meals does not affect the metabolic syndrome score in 8-11-year-old children, but reduces cardiometabolic risk markers despite increasing waist circumference. Br J Nutr 2014;112:1826-36.

25. Morris NM, Udry JR. Validation of a self-administered instrument to assess stage of adolescent development. J Youth Adolesc 1980;9:271-80.
26. Cole TJ, Bellizzi MC, Flegal KM, Dietz WH. Establishing a standard definition for child overweight and obesity worldwide: international survey. BMJ 2000;320:1240-3.

27. Cole TJ, Flegal KM, Nicholls D, Jackson AA. Body mass index cut offs to define thinness in children and adolescents: international survey. BMJ 2007;335:194.

28. VanItallie TB, Yang MU, Heymsfield SB, Funk RC, Boileau RA. Heightnormalized indices of the body's fat-free mass and fat mass: potentially useful indicators of nutritional status. Am J Clin Nutr 1990;52:953-9.

29. Margulies L, Horlick M, Thornton JC, Wang J, Ioannidou E, Heymsfield SB. Reproducibility of pediatric whole body bone and body composition measures by dual-energy X-ray absorptiometry using the GE Lunar Prodigy. J Clin Densitom 2005;8:298-304.

30. Fan J, Zhang J-T. Two-step estimation of functional linear models with applications to longitudinal data. J R Soc Statist Soc Ser B Stat Methodol 2000;62:303-322.

31. Shi M, Weiss RE, Taylor JMG. An analysis of paediatric CD4 counts for acquired immune deficiency syndrome using flexible random curves. J R Soc Statist Soc Ser C Appl Stat 1996;45:151-63.

32. Wu H, Zhang J-T. Local polynomial mixed-effects models for longitudinal data. J Am Statist Assoc 2002;97:883-97.

33. Laursen RP, Dalskov SM, Damsgaard CT, Ritz C. Back-transformation of treatment differences-an approximate method. Eur J Clin Nutr 2014;68:277-80.

34. Silverman BW. The Kernel Method for Univariate Data. Density Estimation for Statistics and Data Analysis. 1st ed. London: Chapman and Hall, 1986:34-74.

35. Loader C. Local Regression and Likelihood. New York: Springer, 1999:101-5.

36. Hothorn T, Bretz F, Westfall P. Simultaneous inference in general parametric models. Biom J 2008;50:346-63. 